\title{
Inhibition of Erythrocyte Sickling In Vitro by Pyridoxal
}

\author{
John A. Kark, Milton P. Kale, Peter G. Tarassoff, Monty Woods, and \\ LAWRENCE S. LESSIN with the technical assistance of CECIL U. HICKS, \\ William A. BELL, and HENRY S. WeEmS, Walter Reed Army Institute of Research, \\ Washington, D. C. 20012, and Department of Medicine, George Washington \\ University Medical Center, Washington, D. C. 20037
}

\begin{abstract}
A B S TRACT To test the antisickling activity of pyridoxal, we compared the oxygen affinity and the percent sickling at low $\mathrm{Po}_{2}$ of untreated erythrocytes with values for cells from the same blood sample incubated with pyridoxal, glyceraldehyde, or pyridoxine. Pyridoxal increased oxygen affinity much more than glyceraldehyde. $20 \mathrm{mM}$ pyridoxal and glyceraldehyde had equivalent antisickling activity. At $\mathrm{Po}_{2}$ levels above $20 \mathrm{~mm} \mathrm{Hg}$, both agents reduced sickling to less than $2 \%$. In samples examined by electron microscopy, pyridoxal reduced the percent sickled cells and the percent cells that contain hemoglobin $\mathrm{S}$ fibers by the same amount (from 74 to 3\%). Pyridoxine had no effect on oxygen affinity or sickling. Pyridoxal reacts with intracellular hemoglobin to increase oxygen affinity, which inhibits hemoglobin $S$ polymerization and sickling.
\end{abstract}

\section{INTRODUCTION}

Erythrocyte sickling is initiated by the polymerization of deoxyhemoglobin S. Although several derivatives of pyridoxal react with hemoglobin $(\mathrm{Hb})^{1}$ and inhibit polymerization of $\mathrm{Hb} \mathrm{S}(1-3)$, none appear promising for clinical use because they are either $B_{6}$ antagonists (e.g., deoxypyridoxal) or they contain polar side chains which limit entry into the erythrocyte (e.g., pyridoxal phosphate). In contrast, pyridoxal is a form of vitamin $B_{6}$ which is actively transported into erythrocytes (4). However, pyridoxal appeared unreactive (5) or reacted so slowly with a dilute solution of $\mathrm{Hb} \mathrm{S} \mathrm{(3)} \mathrm{that} \mathrm{it} \mathrm{was}$ not tested for antisickling activity. Only $10 \%$ of $\mathrm{Hb} \mathrm{S}$

The opinions or assertions contained herein are the private views of the authors and are not to be construed as official or reflecting the views of the Department of the Army or the Department of Defense.

Received for publication 3 July 1978.

${ }^{1}$ Abbreviations used in this paper: AA, normal hemoglobin phenotype; CPD, anticoagulant citrate phosphate dextrose solution; $\mathrm{Hb}$, hemoglobin; $\mathrm{P}_{50}$, the $\mathrm{PO}_{2}$ at which hemoglobin is half saturated; SS, homozygous hemoglobin $\mathrm{S}$ phenotype. was modified after erythrocytes were incubated with 3 $\mathrm{mM}$ pyridoxal (6). In this experiment a large increase in oxygen affinity was noted. This suggested to us that pyridoxal did react extensively with $\mathrm{Hb}$, but the adduct was dissociated in preparing hemolysates for electrofocusing. We therefore examined the effect of pyridoxal on the oxygen affinity of intact erythrocytes and on the percent sickled cells that result from exposure to low $\mathrm{PO}_{2}$. Pyridoxal was compared to glyceraldehyde, another carbonyl compound which had defined antisickling activity $(7,8)$, and with pyridoxine, the alcohol analogue of pyridoxal.

\section{METHODS}

Materials. Pyridoxal hydrochloride, pyridoxine hydrochloride, DL-glyceraldehyde, and bovine serum albumin were obtained from Sigma Chemical Co., St. Louis, Mo. Heparin without preservative was obtained from Flow Laboratories, Rockville, Md. All other chemicals were reagent grade.

Preparation of treated erythrocytes. Venous blood was drawn with informed consent from donors who had a normal Hb phenotype (AA) or a phenotype consistent with homozygous $\mathrm{Hb}$ S (SS), (9). For investigation of antisickling effects, blood was drawn into anticoagulant citrate phosphate dextrose solution (CPD) and stored at $4^{\circ} \mathrm{C}$ for up to 6 days. Erythrocytes were washed three times and suspended at $10 \%$ hematocrit in phosphate buffer that consists of $145.4 \mathrm{mM} \mathrm{NaCl}, 4 \mathrm{mM} \mathrm{KCl}$, $1.65 \mathrm{mM} \mathrm{Na} \mathrm{HPO}_{4}, 0.16 \mathrm{mM} \mathrm{KH} \mathrm{PO}_{4}, 11.1 \mathrm{mM}$ D-glucose, and $50 \mathrm{mg} /$ liter bovine serum albumin. Four reaction mixtures were prepared from each suspension; a control and mixtures with $20 \mathrm{mM}$ pyridoxal, glyceraldehyde, or pyridoxine. The $\mathrm{pH}$ was adjusted to 7.4 and each mixture was adjusted to $290 \pm 2$ mosmol, excluding the compound tested. Reaction mixtures were incubated in a shaking water bath at $37^{\circ} \mathrm{C}$ in dim light for $90 \mathrm{~min}$, transferred to shaking tonometers, and equilibrated for $30 \mathrm{~min}$ at $37^{\circ} \mathrm{C}$ with a humidified mixture of $\mathrm{N}_{2}, \mathrm{O}_{2}$, and $\mathrm{CO}_{2}$. The partial pressure of each gas was varied independently, with an Ohio Medical Products anesthesia machine with modified fittings (Ohio Medical Products Div., Madison, Wis.). Before and after equilibration, the $\mathrm{pH}$ and $\mathrm{PO}_{2}$ were measured in a Corning 161 Blood Gas Analyzer (Corning Medical, Corning Glassworks, Medfield, Mass.) and cells were drawn anaerobically into cold $1 \%$ buffered glutaraldehyde at $\mathrm{pH}$ 7.4. To eliminate the effect of CPD or buffer on erythrocyte oxygen affinity, this ex- 

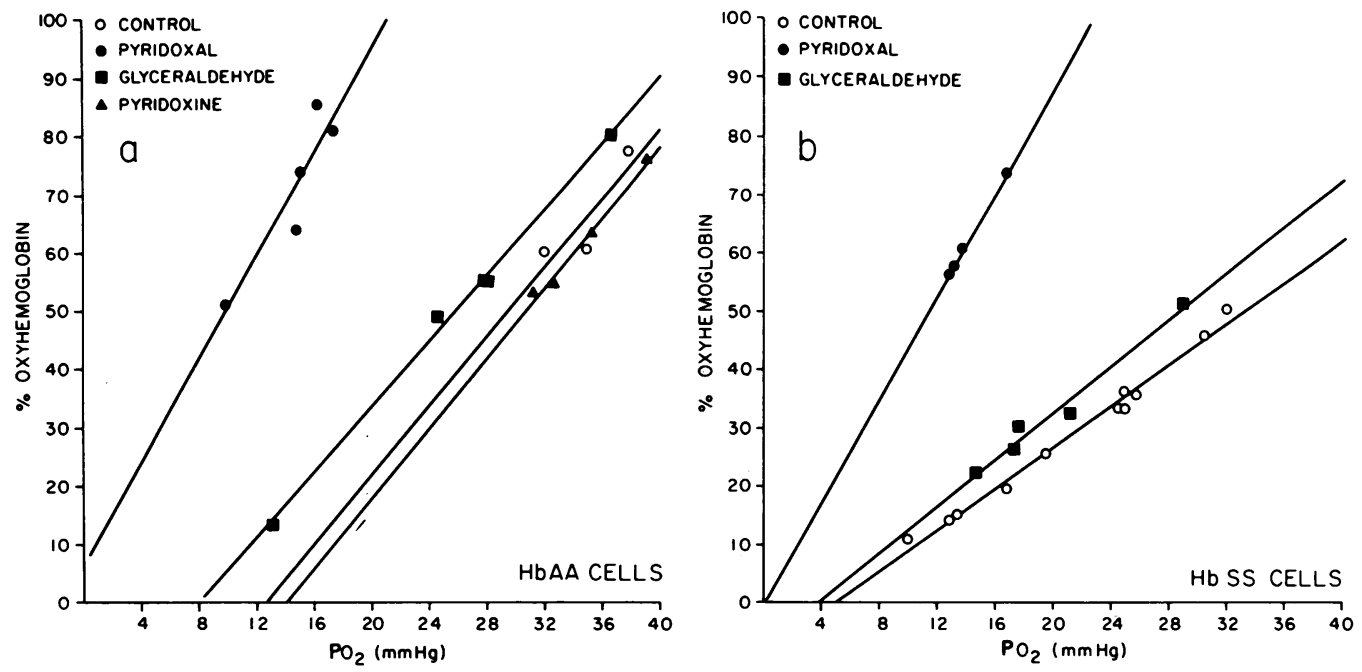

FIGURE 1 Effect of three compounds on the oxygen affinity of whole blood. Points on the linear part of the oxygen dissociation curve were determined after incubation of whole blood untreated or with $20 \mathrm{mM}$ compound added: $(a)$ a single AA blood sample; $(b)$ a single SS blood sample.

periment was repeated with fresh, heparinized whole blood from four SS patients.

Effects on oxygen affinity. Fresh, heparinized whole blood from two AA and two SS individuals was incubated and exposed to low $\mathrm{PO}_{2}$ as described above. The percent oxy-Hb was measured with an IL 182 Co-Oximeter (Instrumentation Laboratory, Inc., Lexington, Mass.) to define the linear portion of the oxygen dissociation curve for each reaction mixture. The $\mathrm{PO}_{2}$ at which $\mathrm{Hb}$ was half saturated $\left(\mathbf{P}_{50}\right)$ was calculated from a linear regression.

Effects on sickling. Two observers counted from 250 to 500 fixed erythrocytes from each reaction mixture with an AO H2l interference microscope (C. Reichert, sold by American
Optical Corp., Scientific Instrument Div., Buffalo, N. Y.) with a $\times 100$ oil immersion objective. The observed variance of the proportion of sickle cells in each sample (as defined by counting subgroups of 50 cells) was close to that predicted by the binomial distribution. Slides with greater variation were prepared again. The number of cells counted was chosen to identify a $20 \%$ decrease in sickling with a false negative rate $<0.05$ and a false positive rate $<0.01(10)$. Erythrocytes were considered reversibly sickled if the cells were spiculated and elongated or had a transparent veil of cytoplasm along one side $(11,12)$.

Fixed erythrocytes from 20 experiments were also examined and photographed in an AMR-1000 scanning elec-
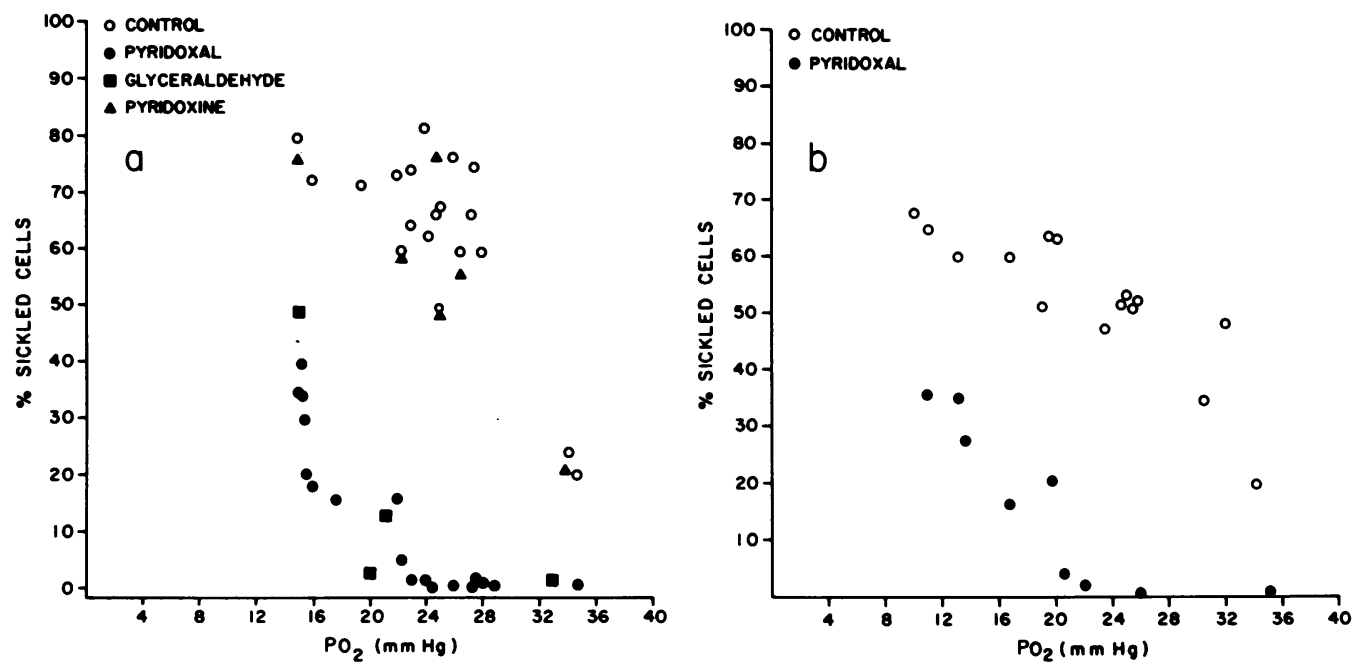

FIGURE 2 Effects of three compounds on erythrocyte sickling at varied oxygen tensions. Erythrocytes were incubated 90 min at $37^{\circ} \mathrm{C}$, untreated or with $20 \mathrm{mM}$ compound, equilibrated at low $\mathrm{PO}_{2}$ for $30 \mathrm{~min}$, fixed, and examined. (a) Studies of cells from eight SS patients with stored, washed cells resuspended in buffer as described in Methods. (b) Studies of fresh, whole SS blood from four patients. 
tron microscope (AMR Corp., Bedford, Mass.) (13). Cells from three experiments were prepared for transmission electron microscopy (14). Thin sections were stained with lead citrate and uranyl acetate, examined, and photographed in an AEI EM 8 electron microscope (AEI Scientific Instruments, San Diego, Calif.).

\section{RESULTS}

Effects on whole blood oxygen affinity. The effects of pyridoxal, glyceraldehyde, and pyridoxine on the oxygen affinity of whole blood are shown in Fig. 1 and analyzed in Table I. Pyridoxal produced a much greater left shift in the oxygen dissociation curves than glyceraldehyde. Pyridoxine had no effect on oxygen affinity.

Effects on erythrocyte sickling. The relation between percent sickling and $\mathrm{PO}_{2}$ was determined for erythrocytes drawn in CPD and suspended in buffer (Fig. 2a). Pyridoxine had no effect on sickling. Plots for pyridoxal and glyceraldehyde were identical, with significant reduction in sickling (pyridoxal, $P<0.001$; glyceraldehyde, $P<0.03$, the sign test). In paired experiments on blood from five patients, the antisickling activity of pyridoxal (percent sickling, mean $\pm S D$, $7.8 \pm 6.4 \%)$ and glyceraldehyde $(19.2 \pm 20.4 \%)$ were not significantly different $(P<0.3$, paired $t$ test). The relation between percent sickling and $\mathrm{PO}_{2}$ was not altered by use of heparinized whole blood (Fig. 2b) instead of erythrocytes in buffer. The following values were observed for blood from four SS patients treated with $5 \mathrm{mM}$ instead of $20 \mathrm{mM}$ pyridoxal: $0.6 \%$ sickling at a $\mathrm{PO}_{2}$ of $35.2 \mathrm{~mm} \mathrm{Hg}, 1.3 \%$ at $26.3 \mathrm{~mm} \mathrm{Hg}, 42 \%$ at $23 \mathrm{~mm}$ $\mathrm{Hg}$, and $64 \%$ at $15 \mathrm{~mm} \mathrm{Hg}$. Sickling of untreated samples was $20,81,65.5$, and $79.3 \%$, respectively.

Scanning electron micrographs of representative samples (Fig. 3) confirmed the differences in degree of sickling noted by interference microscopy.

Effects on $\mathrm{Hb} \mathrm{S}$ fiber formation. In transmission electron micrographs, untreated samples had a much higher proportion of cells that contain intracellular fibers characteristic of $\mathrm{Hb} \mathrm{S}$ polymers (12) than did

TABLE I

$P_{50}$ Values for Normal and Sickle Cell Blood

\begin{tabular}{lrc}
\hline \multirow{2}{*}{\multicolumn{1}{c}{ Agent }} & \multicolumn{2}{c}{ Pso } \\
\cline { 2 - 3 } & As blood & SS blood \\
\hline & & $m m$ Hg \\
Untreated & 29.5 & 33.1 \\
Pyridoxal, $20 \mathrm{mM}$ & 9.9 & 11.4 \\
Glyceraldehyde, $20 \mathrm{mM}$ & 25.7 & 28.6 \\
Pyridoxine, $20 \mathrm{mM}$ & 30.6 & -
\end{tabular}

The $P_{50}$ was calculated from the linear regressions shown in Fig. 1. pyridoxal treated samples. A close correlation was found between the percent cells that contain $\mathrm{Hb} S$ fibers and the percent sickle forms by light microscopy (untreated cells: $75 \%$ Hb S fibers, $72.6 \%$ sickled; pyridoxal treated cells: $2.9 \% \mathrm{Hb} \mathrm{S}$ fibers, $2.4 \%$ sickle forms) (Figs. 3 and 4).

\section{DISCUSSION}

This report provides evidence that pyridoxal inhibits sickling of SS erythrocytes by modification of $\mathrm{Hb} \mathrm{S}$. Pyridoxal reduced the fraction of cells that contain $\mathrm{Hb}$ S fibers at low $\mathrm{Po}_{2}$ from $75 \%$ to $3 \%$. A close correspondence was found between the percent sickled cells and the percent cells that contain $\mathrm{Hb} \mathrm{S}$ fibers. Pyridoxal

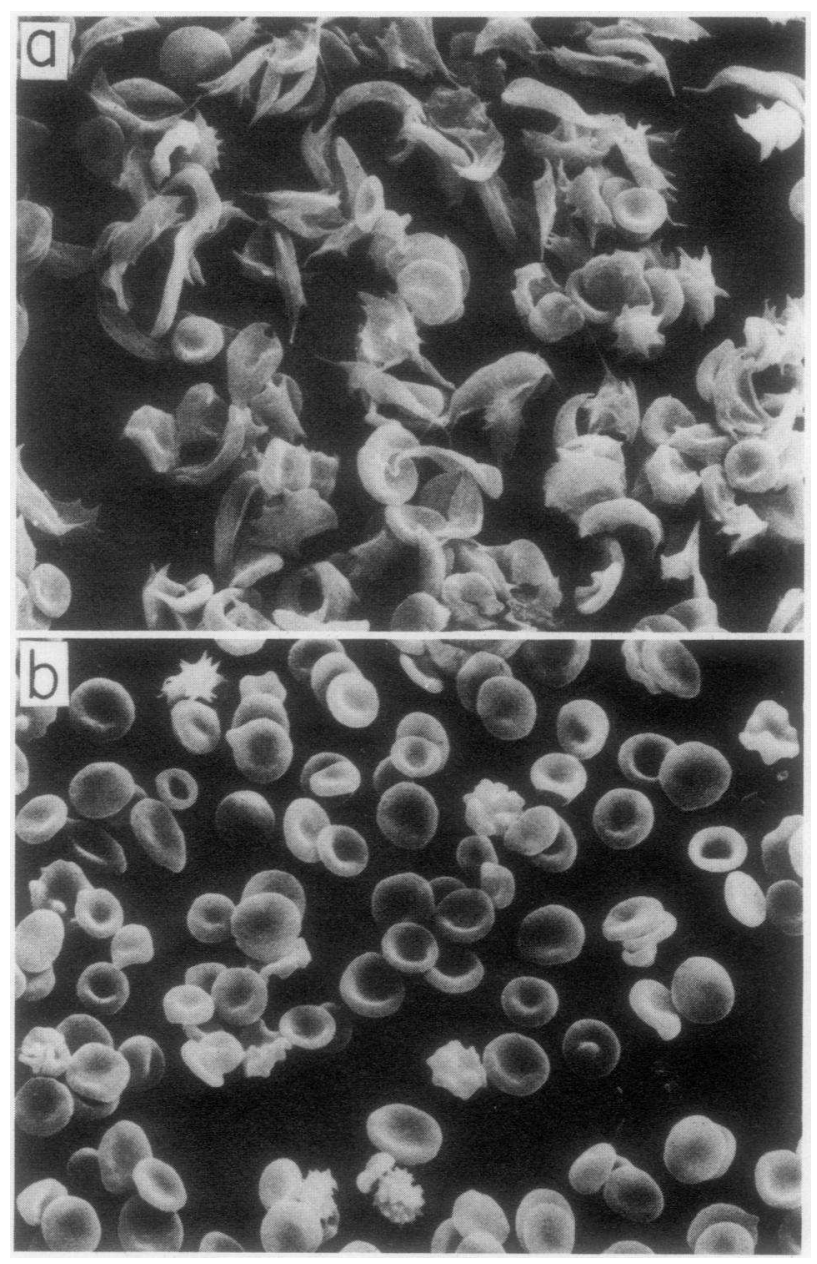

FIGURE 3 Effect of pyridoxal on erythrocyte sickling. Washed erythrocytes from a single SS blood sample were suspended in buffer, incubated untreated or with $10 \mathrm{mM}$ pyridoxal, equilibrated at a $\mathrm{Po}_{2}$ of $23 \mathrm{~mm} \mathrm{Hg}$, and fixed. Scanning electron micrographs at $\times 2,000$ magnification show: (a) untreated cells with about $70 \%$ spiculated sickle forms; (b) pyridoxal treated cells with more than $90 \%$ discocytes, occasional echinocytes, and about $1 \%$ sickle forms. 

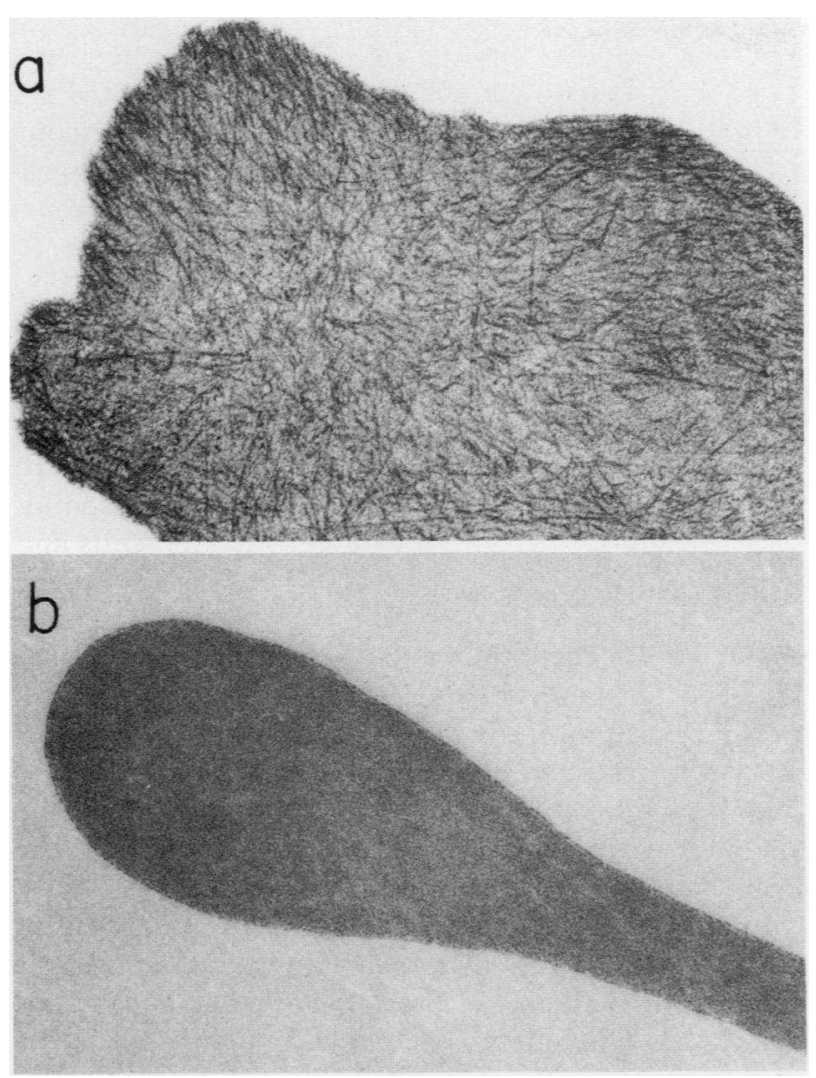

FIGURE 4 Effect of pyridoxal on intracellular fibers. Fixed erythrocytes from the experiment shown in Fig. 3 were sectioned and examined by transmission electron microscopy at $\times 40,000$ magnification. (a) Portion of an untreated cell showing intracellular $\mathrm{Hb} \mathrm{S}$ fibers; $(b)$ Portion of pyridoxaltreated cell, which shows absence of $\mathrm{Hb} \mathrm{S}$ fibers.

reduced the $\mathrm{P}_{50}$ of SS or AA blood by $67 \%$, as reported for AA blood (6). The increase in proportion of oxy-Hb was adequate to explain the antisickling activity of pyridoxal. However, a low $P_{50}$ might complicate the clinical use of pyridoxal by an adverse effect on oxygen delivery and by compensatory erythropoiesis. In contrast, glyceraldehyde did not substantially decrease the $\mathrm{P}_{50}$. Different amino acid residues of $\mathrm{Hb}$ are modified by glyceraldehyde (8) and pyridoxal derivatives $(2,3$, 15). Therefore, it might be possible to modify $\mathrm{Hb}$ with both glyceraldehyde and pyridoxal, perhaps inhibiting sickling with lower doses of each compound.

$20 \mathrm{mM}$ pyridoxal and glyceraldehyde had similar antisickling activity. Studies of control and pyridoxaltreated heparinized whole blood demonstrated that artifacts caused by the storage or processing of erythrocytes were not important. Single observations on blood from four patients showed significant antisickling activity for $5 \mathrm{mM}$ pyridoxal, comparable to published data for deoxypyridoxal (3), $o$-vanillin (6), and salicylaldehyde (6). These results suggest that the antisickling activity of pyridoxal may be equivalent to the activity of these three agents and greater than that of cyanate (6).

\section{ACKNOWLEDGMENTS}

The authors are grateful to Joseph Kurantsin-Mills for advice, to Margaret J. Lloyd for assistance in obtaining blood samples, to Emma Brown, Edward B. Jenkins, and Jose L. Pacana for technical assistance, to Douglas B. Tang for statistical analysis, and to Alan N. Schechter for reviewing the manuscript.

\section{REFERENCES}

1. Benesch, R., R. E. Benesch, and S. Yung. 1974. Chemical modifications that inhibit gelation of sickle hemoglobin. Proc. Natl. Acad. Sci. U. S. A. 71: 1504-1505.

2. Benesch, R. E., S. Yung, T. Suzuki, C. Bauer, and R. Benesch. 1973. Pyridoxal compounds as specific reagents for the alpha and beta N-termini of hemoglobin. Proc. Natl. Acad. Sci. U. S. A. 70: 2595-2599.

3. Benesch, R., R. E. Benesch, R. Edalji, and T. Suzuki. 1977. 5 '-Deoxypyridoxal as a potential anti-sickling agent. Proc. Natl. Acad. Sci. U. S. A. 74: 1721-1723.

4. Yamada, K., and M. Tsuji. 1968. Transport of vitamin $B_{6}$ in human erythrocytes. J. Vitaminol. (Kyoto). 14: 282294.

5. Benesch, R. E., R. Benesch, A. Bank, R. Renthal, and B. A. Bray. 1971. The preparation and properties of pyridoxylated hemoglobin. In Genetical, Functional, and Physical Studies of Hemoglobins. T. Arends, G. Bemski, and R. L. Nagel, editors. S. Karger, White Plains, N. Y. $134-142$.

6. Zaugg, R. H., J. A. Walder, and I. M. Klotz. 1977. Schiff base adducts of hemoglobin, modifications that inhibit erythrocyte sickling. J. Biol. Chem. 252: 8542-8548.

7. Nigen, A. M., and J. M. Manning. 1977. Inhibition of erythrocyte sickling in vitro by DL-glyceraldehyde. Proc. Natl. Acad. Sci. U. S. A. 74: 367-371.

8. Nigen, A. M., and J. M. Manning. 1978. Effects of glyceraldehyde on the structural and functional properties of sickle erythrocytes. J. Clin. Invest. 61: 11-19.

9. Schmidt, R. M., and E. M. Brosious. 1976. Basic Laboratory Methods of Hemoglobinopathy Detection. Department of Health, Education, and Welfare Publication 76-8266 (Center for Disease Control) Bethesda, Md. 8th edition. 1-64.

10. Burdette, W. J., and E. A. Gehan. 1976. Planning and Analysis of Clinical Studies. Charles C. Thomas Publisher, Springfield, Ill. 92.

11. Padilla, F., P. A. Bromberg, and W. M. Jensen. 1973. The sickle-unsickle cycle: a cause of cell fragmentation leading to permanently deformed cells. Blood. 41: 653660.

12. White, J. G. 1974. Ultrastructural features of erythrocyte and hemoglobin sickling. Arch. Intern. Med. 133: 545562.

13. Bessis, M., and R. I. Weed. 1972. Preparation of red blood cells (RBC) for SEM: A survey of various artifacts. In Scanning Electron Microscopy (Part II). Proc. of the Workshop on Biological Specimen Preparation Techniques for Scanning Electron Microscopy. O. Johri and I. Corvin, editors. Illinois Institute of Technology Research Inst., Chicago, Ill. 289-296.

14. Luft, J. H. 1961. Improvements in epoxyresin embedding methods. J. Biophys. Biochem. Cytol. 9: 409-411.

15. Arnone, A., R. E. Benesch, and R. Benesch. 1977. Structure of human deoxyhemoglobin specifically modified with pyridoxal compounds. J. Mol. Biol. 115: 627-642. 